Published in final edited form as:

J Pediatr Gastroenterol Nutr. 2012 October ; 55(4): 425-428. doi:10.1097/MPG.0b013e318253f2f0.

\title{
Quality of Life in Patients Post Colectomy for Pediatric Onset Ulcerative Colitis
}

\author{
Deepal H. Dalal, BS, Dana Patton, MD, Janet M. Wojcicki, PhD, MPH, Ann L. Clark, BS, \\ Elizabeth A. Garnett, BA, and Melvin B. Heyman, MD, MPH \\ Department of Pediatrics University of California, San Francisco
}

\begin{abstract}
Background-Ulcerative colitis in children can have a negative impact on quality of life (QOL).

Methods-We included 16 of 31 patients who underwent colectomy for ulcerative colitis before 20 years of age between 1980-2005 at UCSF Benioff Children's Hospital. A disease-specific QOL questionnaire (IBDQ-32), validated for adults, was used to determine QOL and an additional questionnaire addressing bowel function and reproductive health in long term follow up of these patients.
\end{abstract}

Results-Median age at the time of survey was 20.3 years (17.9-25.3) and time post colectomy was 6.9 years (4.8-9.0). Mean total score was $159.7 \pm 43.3$ (58-210). Two patients (12.5\%) had scores of $\geq 200,12(75.0 \%)$ had 101-199, and $2(12.5 \%)$ had $\leq 100$. Patients $\leq 18$ years at the time of survey showed higher QOL, particularly in emotional health $(\mathrm{p}=0.020)$, social function $(\mathrm{p}=0.014)$, and overall QOL $(\mathrm{p}=0.009)$. Social function scored highest of all systems (median 7; IQR 4-7). Patients with scores $\leq 00$ had repeated episodes of pouchitis (16-30) compared with the other 14 patients (0-3). Children diagnosed $₫ 2$ years of age tended to have higher QOL $(\mathrm{p}=0.072)$. Years post-colectomy did not correlate to QOL. Eleven patients were sexually active. Two males had feelings of impotence and decreased libido, and six females experienced dyspareunia. Three women tried unsuccessfully to conceive after colectomy. One woman became pregnant four times, each leading to miscarriage.

Conclusions-Younger age at time of colectomy, diagnosis, and survey show higher QOL. Highest satisfaction was found in ability to attend school, work, and social engagements. Pouchitis continued to be an issue for a small number of the patients, with two patients having recurring episodes that severely affected QOL. Patients reported decreased sexual activity and fertility at the time of survey due to colectomy, especially for females.

Correspondence to: Melvin B. Heyman, MD, MPH., Division of Pediatric Gastroenterology, Hepatology and Nutrition, University of California, 500 Parnassus Ave, MU 4-East, Box 0136, San Francisco, CA 94143-0136, Phone: 415-476-5892, Fax: 415-476-1343, mheyman@peds.ucsf.edu.

Supplemental digital content is available for this article. Direct URL citations appear in the printed text, and links to the digital files are provided in the HTML text of this article on the journal's Web site (www.jpgn.org).

No authors have any conflicts of interest related to this report.

This is a PDF file of an unedited manuscript that has been accepted for publication. As a service to our customers we are providing this early version of the manuscript. The manuscript will undergo copyediting, typesetting, and review of the resulting proof before it is published in its final citable form. Please note that during the production process errors may be discovered which could affect the content, and all legal disclaimers that apply to the journal pertain. 


\section{Keywords}

Inflammatory Bowel Disease; Children; Adolescents; Fertility; Sexual Function; Surgery for IBD; Fertility; Complications of IBD; Pouchitis

\section{Introduction}

Pediatric patients with chronic ulcerative colitis (UC) experience frequent disease flares, regular doctor visits, long-term care, occasional procedures, hospitalizations, and interruption of life plans that can have a negative impact on their quality of life (QOL). ${ }^{1,2,3}$ Surgical resection of the large intestine offers a "cure" for their disease. Surgery is typically performed when a patient remains symptomatic or has complications of the disease despite ongoing, often intensive medical therapy. ${ }^{4,5}$ Colectomy is often performed in patients who desire to ultimately eradicate their disease due to poor response to medical management. ${ }^{6}$ Colectomy can restore patient health from acute or chronic disease and minimize the risk of cancer of the large bowel in patients with UC. ${ }^{5}$

To date, however, limited and conflicting data to document UC patients who undergo this major procedure when onset is during childhood. Chronic ulcerative colitis in children can have a negative impact on QOL. Evaluation of QOL post-colectomy might help physicians gain insight into the problems that arise after surgery. Health-related QOL improvements were seen as early as 1 month postoperatively. ${ }^{8}$ Studies in adults suggest that colectomy leads to improvement in QOL to levels similar to the general population. ${ }^{1,7,9} \mathrm{In}$ an adult sample of 645 patients, 93\% demonstrated a good QOL, mainly improving 1 year after surgery as patients return to a normal lifestyle. ${ }^{7}$

We studied a subset of patients included in a previous retrospective study reporting postsurgery complications in 31 UC patients at the University of California in San Francisco (UCSF). ${ }^{10}$ We used a validated, disease specific QOL questionnaire ${ }^{11}$ to further describe different age groups at diagnosis and colectomy and associations with quality of life in pediatric patients with ulcerative colitis.

\section{Methods}

Pediatric patients under 20 years of age at the time of colectomy with IBD who underwent colectomy between 1980 and 2005 at the UCSF Benioff Children's Hospital were recruited via mailed letters. Patients were identified by retrospective chart review in the UCSF Department of Surgery, Division of Pediatric Gastroenterology, Hepatology and Nutrition, and Health Information Management Systems (medical records).

All patients who were diagnosed with UC before age 18 and who had a colectomy before their $20^{\text {th }}$ birthday were eligible for enrollment. Twenty-eight patients deemed eligible for the study were mailed a letter describing the study and a consent form. Patients were then contacted by telephone to further explain the study. Updated contact information was not available for 5 patients, 7 patients did not respond to our mailing, and informed consent was obtained from 16. Following consent, the study coordinator completed the IBDQ-32 
validated questionnaire for patients with inflammatory bowel disease (IBDQ-32; McMaster University in Ontario, Canada) ${ }^{11}$ and a supplemental questionnaire that addressed bowel function and reproductive health, developed by the authors. The same study coordinator administered all questionnaires via telephone. Additional data were collected by retrospective chart review. The project was approved by the UCSF Committee on Human Research.

IBDQ-32 was measured to assess four primary categories: bowel system (frequent stools, loose stools and abdominal pain), emotional health (irritability, anger and depression), systemic system (fatigue, difficulty sleeping and maintaining weight), and social function (attending social engagements, work or school). ${ }^{12}$ The IBDQ-32 addressed 10 bowel system, 5 systemic system, 12 emotional function, and 5 social function questions. Each question was rated on a scale of 1 ("all of the time") to 7 ("none of the time"). Total scores ranged from 32 to 224 , higher scores indicating a better QOL. The maximum possible scores in each system were as follows: 70 for bowel systems, 35 for systemic systems, 84 for emotional function, and 35 for social function. We reported patient's total QOL scores based on classification by Meyer et al ( $2200=$ excellent, 101-199=good or regular, $₫ 00=$ bad). ${ }^{13}$ Two additional categories, bowel anastomosis function (pouchitis, accidental leakage and urge for defecation) and reproductive health (infertility, conception and sexual function), were included in a supplemental questionnaire (see online-only Appendix, http:// links.lww.com/MPG/A108) that included quantitative questions such as number of children and episodes of Pouchitis. Subjects under age 18 at the time of the survey were interviewed the same as other participants except they were not asked questions regarding sexual function. Data were analyzed using Mann Whitney U Rank Sum Test. Results are presented as median and interquartile range (IQR).

\section{Results}

\section{Demographics and Patient Characteristics}

Sixteen patients (6 male) were enrolled in the study. Thirteen patients (81.3\%) were Caucasian and three (18.7\%) were African-American. The survey was administered at a median age of 20.3 years (17.9-25.3) and 6.9 (IQR 4.8-9.0) years post-colectomy. Five patients were $\leq 18$ at the time of survey (Table 1).

\section{QOL Findings}

Children who underwent colectomy and were diagnosed $₫ 2$ years of age had slightly (nonsignificantly) higher QOL. QOL scores were not associated with age at the time of colectomy or age at diagnosis. (Table 2,3) Years post colectomy associated with QOL systems did not yield significant results. Patients $\leq 8$ years at the time of survey showed higher QOL in all categories, significance achieved in emotional health $(\mathrm{p}=0.020)$, social function ( $\mathrm{p}=0.014)$, and overall QOL ( $\mathrm{p}=0.009)$. (Figure)

Total scores were 173.0 (IQR 154.5 - 186.8, total range 58 - 210). Two patients (12.5\%) had overall IBDQ scores of 2200 , twelve (75.0\%) had scores of 101-199, and two (12.5\%) had scores $\leq 100$. According to Meyer et al classification, $12.5 \%$ of patients had excellent 
QOL, while $12.5 \%$ had bad QOL. The youngest patient in our study, who was 3 years at diagnosis, 6 years at colectomy, and 10 years at survey, had the highest overall QOL score of 210 of the possible 224 . No differences were found comparing males and females. Social Function was scored the highest of all systems (median 7; IQR 4-7). Six of the 16 patients had a score of 7 across all social function questions, not found for any other system.

\section{Colectomy}

Ileal Pouch-anal Anastomosis (IPAA) total colectomy with a functional J-pouch was performed in 15/16 (93.8\%) patients; one had a Hartmann pouch. A majority (13/16, 81.3\%) of patients had hand-sewn anastomosis. Nine patients had an elective colectomy, and seven had an urgent colectomy. Ten patients had either a laparoscopic or laparoscopic-assisted colectomy, while 6 had an open colectomy. 8/16 patients had a 1 stage planned operation, 5 had a 2-stage, and 3 had a 3 -stage planned operation. None of the operative factors correlated with QOL.

The QOL questionnaire showed that 2 patients were concerned about having surgery after colectomy. All but 5 reported having at least one surgery since colectomy, and one patient had 11 surgeries. Six patients reported a small bowel obstruction post colectomy; one had 10 episodes. These did not correlate with QOL.

\section{Pouchitis}

Pouchitis was reported by 9 patients (56.3\%). The two patients with overall QOL scores $\checkmark 00$ had repeated episodes of pouchitis compared with the other 14 patients. One patient had 16 episodes of pouchitis (Patient 1), while the other had 30 (Patient 2). (Table 4) Both patients were African-American. Patient 1 was male, 13 at the time of colectomy and 33 at the time of survey. Patient 2 was female, 19 at the age of colectomy and 24 at the time of survey. Patient 1 had a 3-stage total colectomy with ileostomy, while Patient 2 had a 2-stage laparoscopic assisted total colectomy with ileostomy. Both patients reported problems with fatigue, waking up in the middle of the night, and maintaining weight most or all the time (lowest systemic system scores).

Patient 2 was the only patient in our cohort who had a colectomy over 18 years of age (age 19) and the greatest number of complications post colectomy. The subject had 30 pouchitis episodes and 1 small bowel obstruction within 5 years post colectomy. After 2 successful pregnancies before colectomy, the patient was unable to become pregnant post colectomy and felt that colectomy had severely restricted sexual function. This patient had the lowest scores of 1 across all systemic system domains.

\section{Sexual Activity and Childbearing Abilities}

Seven females and four males were sexually active at the time of the survey. Of those eleven patients, six females and two males felt that their sexual activity was somewhat to severely affected by their colectomy. The two males had feelings of impotence and decrease libido, while the six females experienced dyspareunia. 
One female and two males had at least one child at the time of survey. The two male patients each had one child post colectomy, but the female patient (patient 2) was infertile despite trying consistently and having two children before colectomy. Three females were trying to become pregnant at the time of survey, and none of the males. Of the three women including patient 2 who tried to have children after colectomy, none were able to successfully conceive a child. One woman became pregnant four times, each leading to a miscarriage.

\section{Discussion}

Our study of 16 patients who underwent colectomy before 20 years of age showed that QOL was highest among children diagnosed and who underwent colectomy prior to 13 years of age compared with older patients. A younger age ( $\leq 8$ years) at the time of survey also showed a significantly higher QOL. Highest satisfaction was found in ability to attend school, work, and social engagements. Pouchitis was an issue for most of the patients, two patients suffering from recurring episodes.

Our study, while small, supports prior reports of decreased sexual function, including fertility and rate of conception especially in females following IPAA for UC. ${ }^{14-18}$ Cornish et al recently reported an increase from 12 to 26 percent of infertility rate following restorative proctocolectomy among 945 patients, ${ }^{19}$ and Waljee et al reported a threefold increased risk for infertility in women with UC following IPAA. ${ }^{20}$ Our study showed that women may have difficulty conceiving and are potentially at increased risk for miscarriages. Sexual function was decreased in 2 of 4 sexually active males, but it did not seem to affect ability to conceive children, as reported by the two males who conceived children after colectomy.

Few prior studies have been published that investigate QOL for children who undergo colectomy. In one study, Richards et al (2001) concluded that chronic ulcerative colitis patients who undergo IPAA with a functional pouch have $92 \%$ chance of a normal QOL. ${ }^{6}$ Hahnloser et al reported a normal QOL for patients 15 years after IPAA. They also observed that $92 \%$ of patients stayed in the same employment, and $83 \%$ of patients' work was unaffected by the surgery. ${ }^{21}$ Other investigators report that although IPAA patients have a QOL similar to general healthy population, one third of the patients with IPAA have bowel dysfunction that negatively affects their daily lives, with $65 \%$ having 5 to 10 bowel movements a day. ${ }^{22}$ Lichtenstein et al elaborated further by stating that UC surgery does not constitute a cure, restore bowel function or QOL to normal levels, and can introduce additional negative problems with sexual function and fertility. ${ }^{1}$

Data in adults suggest that patients after surgery have improved QOL. ${ }^{1,6,7,13,21}$ Our study found that younger age at the time of colectomy, diagnosis, and survey show better QOL than older age. Females have lower sexual function and fertility, while males have decreased sexual function but appear capable of conceiving a child. Pouchitis appears to detract from improved QOL overall.

Patients considering colectomy as treatment for UC lack knowledge of QOL on a long postoperative period (5 years, 6-10 years, 11-15 years, and 16 or more years after surgery). Our analysis was limited due to the small sample size and lack of longitudinal data and 
psychometric testing. We were also limited due to a varied patient population (age at survey, age at surgery) and that data were retrospectively collected with the possibility of recall bias. Certainly a larger longitudinal study to assess each patient's QOL before and after colectomy in childhood could improve the ability of patients and families to make the decision to undergo colectomy.

\section{Supplementary Material}

Refer to Web version on PubMed Central for supplementary material.

\section{Acknowledgments}

We acknowledge funding support from National Institutes of Health grants DK060617 (DHD, EAG, MBH) and DK08085 (JMW).

\section{References}

1. Lichtenstein GR, Cohen R, Yamashita B, et al. Quality of life after proctocolectomy with ileoanal anastomosis for patients with ulcerative colitis. J Clin Gastroenterol. 2006; 40:669-677. [PubMed: 16940876]

2. Perrin JM, Kuhlthau K, Chughtai A, et al. Measuring quality of life in pediatric patients with inflammatory bowel disease: psychometric and clinical characteristics. J Pediatr Gastroenterol Nutr. 2008; 46:164-71. [PubMed: 18223375] J Pediatr Gastroenterol Nutr. 2008; 46:482. Erratum in:

3. Heyman MB, Kirschner BS, Gold BD, et al. Children with early-onset inflammatory bowel disease (IBD): analysis of a pediatric IBD consortium registry. J Pediatr. 2005; 146:35-40. [PubMed: 15644819]

4. Lashner BA. When should prophylactic colectomy be considered in patients with ulcerative colitis? Cleve Clin J Med. 2003; 70:221-222. [PubMed: 12678211]

5. Lee EC, Truelove SC. Proctocolectomy for ulcerative colitis. World J Surg. 1980; 4:195-201. [PubMed: 7405257]

6. Richards DM, Hughes SA, Irving MH, et al. Patient quality of life after successful restorative proctocolectomy is normal. Colorectal Dis. 2001; 3:223-226. [PubMed: 12790963]

7. Fazio VW, Ziv Y, Church JM, et al. Ileal pouch-anal anastomoses complications and function in 1005 patients. Ann Surg. 1995; 222:120-127. [PubMed: 7639579]

8. Muir AJ, Edwards LJ, Sanders LL, et al. A prospective evaluation of health-related quality of life after ileal pouch anal anastomosis for ulcerative colitis. Am J Gastroenterol. 2001; 96:1480-1485. [PubMed: 11374686]

9. Berndtsson I, Oresland T. Quality of life before and after proctocolectomy and IPAA in patients with ulcerative proctocolitis--a prospective study. Colorectal Dis. 2003; 5:173-179. [PubMed: 12780909]

10. Patton D, Gupta N, Wojcicki JM, et al. Postoperative outcome of colectomy for pediatric patients with ulcerative colitis. J Pediatr Gastroenterol Nutr. 2010; 51:151-4. [PubMed: 20410838]

11. Guyatt G, Mitchell A, Irvine EJ, et al. A new measure of health status for clinical trials in inflammatory bowel disease. Gastroenterology. 1989; 96:804-810. [PubMed: 2644154]

12. Irvine EJ. Quality of life--measurement in inflammatory bowel disease. Scand J Gastroenterol Suppl. 1993; 199:36-39. [PubMed: 8171299]

13. Meyer AL, Teixeira MG, de Almeida MG, et al. Quality of life in the late follow-up of ulcerative colitis patients submitted to restorative proctocolectomy with sphincter preservation over ten years ago. Clinics (Sao Paulo). 2009; 64:877-883. [PubMed: 19759881]

14. Tiainen J, Matikainen M, Hiltunen KM. Ileal J-pouch-anal anastomosis, sexual dysfunction, and fertility. Scand J Gastroenterol. 1999; 34:185-188. [PubMed: 10192198] 
15. Gorgun E, Remzi FH, Goldberg JM, et al. Fertility is reduced after restorative proctocolectomy with ileal pouch anal anastomosis: a study of 300 patients. Surgery. 2004; 136:795-803. [PubMed: 15467664]

16. Johnson P, Richard C, Ravid A, et al. Female infertility after ileal pouch-anal anastomosis for ulcerative colitis. Dis Colon Rectum. 2004; 47:1119-1126. [PubMed: 15164254]

17. Lepisto A, Sarna S, Tiitinen A, et al. Female fertility and childbirth after ileal pouch-anal anastomosis for ulcerative colitis. Br J Surg. 2007; 94:478-482. [PubMed: 17310506]

18. Kwan LY, Mahadevan U. Inflammatory bowel disease and pregnancy: An update. Expert Rev Clin Immunol. 2010; 6:643-657. [PubMed: 20594137]

19. Cornish JA, Tan E, Teare J, et al. The effect of restorative proctocolectomy on sexual function, urinary function, fertility, pregnancy and delivery: a systematic review. Dis Colon Rectum. 2007; 50:1128-1138. [PubMed: 17588223]

20. Waljee A, Waljee J, Morris AM, et al. Threefold increased risk of infertility: a meta-analysis of infertility after ileal pouch anal anastomosis in ulcerative colitis. Gut. 2006; 55:1575-1580. [PubMed: 16772310]

21. Hahnloser D, Pemberton JH, Wolff BG, et al. Results at up to 20 years after ileal pouch-anal anastomosis for chronic ulcerative colitis. Br J Surg. 2007; 94(3):333-340. [PubMed: 17225210]

22. Wuthrich P, Gervaz P, Ambrosetti P, et al. Functional outcome and quality of life after restorative proctocolectomy and ileo-anal pouch anastomosis. Swiss Med Wkly. 2009; 139:193-197. [PubMed: 19350425] 


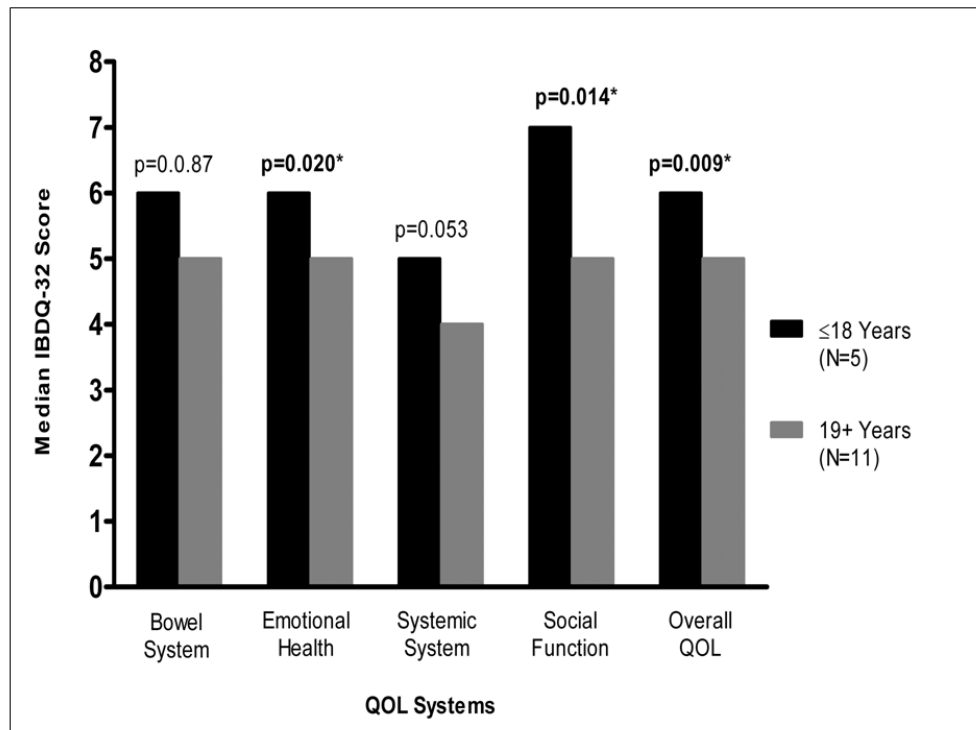

Quality of Life at Age of Survey. Younger age was associated with higher QOL in social function, emotional health, and overall QOL. 


\section{Table 1}

Patient Characteristics

\begin{tabular}{|c|c|}
\hline & Median (IQR) \\
\hline Age at Diagnosis (yrs) & $\mathbf{1 1 . 2}(\mathbf{9 . 5}-14.3)$ \\
\hline$\unlhd 2(\mathrm{~N}=9)$ & $9.8(8.2-10.9)$ \\
\hline $13+(\mathrm{N}=7)$ & $14.7(13.7-15.5)$ \\
\hline Age at Colectomy (yrs) & $\mathbf{1 3 . 9}(\mathbf{1 1 . 3}-16.8)$ \\
\hline$\unlhd 2(\mathrm{~N}=6)$ & $9.1(9.0-11.3)$ \\
\hline $13+(\mathrm{N}=10)$ & $16.7(14.4-17.1)$ \\
\hline Age at Survey (yrs) & $\mathbf{2 0 . 3}(\mathbf{1 7 . 9 - 2 5 . 3})$ \\
\hline$\unlhd 18(\mathrm{~N}=5)$ & $16.3(16.1-17.2)$ \\
\hline $19+(\mathrm{N}=11)$ & $24.8(20.3-25.7)$ \\
\hline Time Post-Colectomy $(\mathbf{y r s})$ & $\mathbf{6 . 9}(\mathbf{4 . 8}-9.0)$ \\
\hline$\unlhd 18(\mathrm{~N}=14)$ & $6.0(4.5-8.0)$ \\
\hline $19+(\mathrm{N}=2)$ & $22.1(20.9-23.4)$ \\
\hline
\end{tabular}

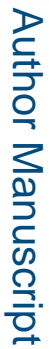

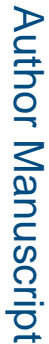

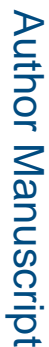




\section{Table 2}

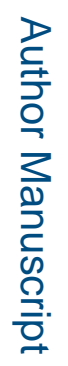

Age at Colectomy by QOL Systems

\begin{tabular}{|l|c|c|c|}
\hline & \2 Years & 13+ Years & \\
\cline { 2 - 4 } & Median Score (IQR) & Median Score (IQR) & p \\
\hline Bowel System & $6(5-7)$ & $5(3-7)$ & 0.113 \\
\hline Emotional Health & $6(5-7)$ & $5(3-7)$ & 0.303 \\
\hline Systemic System & $5(4-6)$ & $4(1-5)$ & 0.587 \\
\hline Social Function & $7(6-7)$ & $7(4-7)$ & 0.403 \\
\hline Overall QOL & $6(4-7)$ & $5(3-7)$ & 0.193 \\
\hline
\end{tabular}


Table 3

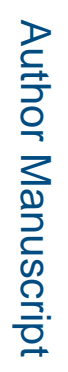

Age at Diagnosis by QOL Systems

\begin{tabular}{|l|c|c|c|}
\hline & \$2 Years & 13+ Years & \\
\cline { 2 - 4 } & Median Score (IQR) & Median Score (IQR) & $\mathbf{p}$ \\
\hline Bowel System & $6(5-7)$ & $5(3-7)$ & 0.079 \\
\hline Emotional Health & $6(5-7)$ & $5(2-6)$ & 0.081 \\
\hline Systemic System & $5(4-6)$ & $4(1-5)$ & 0.185 \\
\hline Social Function & $7(6-7)$ & $6(3-7)$ & 0.276 \\
\hline Overall QOL & $6(5-7)$ & $5(2-6)$ & 0.072 \\
\hline
\end{tabular}


Table 4

Recurrence of Pouchitis by QOL Scores

\begin{tabular}{|l|c|c|}
\hline QOL Total Scores & Pouchitis (N=9) & Number of Episodes (Range) \\
\hline $\mathbf{4 0 0}$ & 2 & $16-30$ \\
\hline $\mathbf{1 0 1 - 1 9 9}$ & 2 & $0-2$ \\
\hline $\mathbf{2 0 0}$ & 5 & $0-3$ \\
\hline
\end{tabular}

